\title{
A história na primeira pessoa: em torno do método de Rithy Panh
}

\section{Anita Leandro}

\section{Resumo}

Sobrevivente da revolução do Khmer Vermelho, que eliminou grande parte da população do Camboja entre 1975 e 1979, o cineasta Rithy Panh consagrou sua obra a esse capítulo trágico da história de seu país. Por que, então, somente depois de já ter sido consagrado como um dos maiores cineastas contemporâneos, com cerca de vinte filmes, ele assume, no documentário $A$ imagem que falta (2013), uma narrativa na primeira pessoa? A história do genocídio cambojano se confunde com a de sua própria família, e até que ele pudesse dizer "eu" na elaboração de uma memória histórica, foi preciso, antes, fazer falar os documentos e as fontes orais, em um minucioso trabalho de escuta do outro, iniciado desde o final dos anos 1980. Retomamos, aqui, o conjunto de sua obra, examinando as passarelas construídas pelo realizador entre sua história pessoal e a história de seu país.

\section{Palavras-Chave}

Rithy Panh. Arquivos. Memória histórica.

Anita Leandro I anita.sleandro@gmail.com Professora associada na Escola de Comunicação da Universidade Federal do Rio de Janeiro - UFRJ, Brasil. É documentarista e autora de diversos artigos sobre cinema. Desenvolve pesquisa sobre a montagem cinematográfica, imagens de arquivo e memória histórica.

\section{1 "Eu" é um outro}

Como contar a história na primeira pessoa, com os meios do cinema, sem transformar a escrita em uma atividade privada, destituída da dimensão coletiva e compartilhável que deve acompanhar a narrativa histórica? Ele próprio um sobrevivente do processo de extermínio da burguesia cambojana liderado por Pol Pot, 0 cineasta Rithy Panh dedicou sua vida à reunião de documentos e testemunhos. Seus filmes e sua pesquisa anteciparam-se ao trabalho da arquivologia e da historiografia na preservação dos arquivos, na escuta dos sobreviventes e na abordagem de aspectos ainda obscuros da história recente do país. Ao longo da década de 1970, mais de um terço da população do Camboja morreu em sucessivas guerras. Rithy Panh perdeu sua família entre 1975 e 1979, período em que a organização comunista pró-chinesa Khmer Vermelho governou o país e durante 0 qual morreram um milhão e oitocentas mil pessoas. A memória ainda não foi suficientemente elaborada, o primeiro julgamento dos responsáveis só aconteceu em 2009, e a fala das testemunhas ainda sofre ameaças. 
Tudo isso confere uma base moral e política ao método de trabalho de Rithy Panh, próximo, em vários aspectos, dos procedimentos de alguns historiadores contemporâneos, interessados pelas imagens e pelas fontes orais.

Com exceção de Souleymane Cissé (1990), retrato do cineasta maliano feito para a série Cinema, do nosso tempo, realizada por André Labarthe, os outros 18 filmes dirigidos por Rithy Panh de 1988 a 2013 são, de uma forma ou de outra, um retorno aos acontecimentos históricos que ele testemunhou ainda criança. Mesmo quando seus filmes abordam questões mais atuais, como a Aids entre jovens prostitutas cambojanas (Papel não embrulha brasa, 2007) ou a abertura de valas nas cidades e nos campos para a instalação de cabos de fibra ótica no Camboja (A terra das almas errantes, 1999), os vestígios da guerra, sepultados às pressas, voltam à superfície, para se inscreverem na paisagem, nas falas e nos corpos mutilados. Na obra de Panh, não há presente sem as marcas do passado, e cada filme é o resultado de um trabalho reiterado de luto por parte dos personagens e do próprio cineasta. Depois da destruição, depois de ter perdido seus pais, irmãos, parentes, amigos e a própria infância durante a revolução, Rithy Panh, que define o cinema como lápide, encontra no trabalho com as imagens a possibilidade de ter novamente um nome, um rosto, uma língua, um país, enfim, um passado no qual se apoiar, uma chave para compreender a história do Camboja e a sua própria história de vida, intimamente ligada à tragédia nacional. Ele diz que faz filmes contra o esquecimento. "Trinta anos depois, os khmers vermelhos continuam vitoriosos: os mortos estão mortos e foram apagados da superfície da terra. Sua lápide, somos nós" (PANH, 2011, p. 205).

Durante os quatro anos de guerra revolucionária, Rithy Panh, ainda menino, não foi mais à escola e viveu sob um regime de terror, em que o silêncio era a norma. Um dos dez filhos de Panh Lauv, professor de origem camponesa e funcionário respeitado do Ministério da Educação, Rithy Panh tinha apenas onze anos quando o Khmer Vermelho, grupo maoísta criado na clandestinidade nos anos 1960, chegou à capital Phnom Penh, em 17 de abril de 1975, um dia antes do seu aniversário. Com o apoio da China e um exército de camponeses, adolescentes, em sua maioria, o Khmer Vermelho pôs fim à ditadura do general Lon Nol, anticomunista aliado aos Estados Unidos, que governava o Camboja desde 1970. Em cinco anos, o regime de Lon Nol e o governo norte-americano, que repetia no Camboja a mesma guerra de ofensiva aérea perpetrada contra o povo vietnamita (a estratégia do "tapete de bombas"), haviam feito seiscentos mil mortos e mais de um milhão de feridos no país. Em meio a esse massacre da população, o Khmer Vermelho toma 0 poder em 1975, com apoio popular, principalmente no campo, onde a amplitude do desastre era maior. Apesar da adesão de setores mais esclarecidos da burguesia cambojana ao processo revolucionário, o Khmer Vermelho inicia, rapidamente, uma limpeza política que prevê a destruição das elites 
e de suas bases de sustentação - família, dinheiro, propriedade privada, tradições, profissionais liberais, intelectuais, artistas, funcionários públicos. A capital, Phnom Penh, é esvaziada em 24 horas e todos os seus habitantes deportados, enviados para campos de trabalho e de reeducação ou, então, presos, torturados e executados. Em menos de um ano, quase toda a família de Rithy Panh - pai, mãe, quatro irmãs e três sobrinhos - morre de fome e de doenças, em decorrência da deportação. Seu irmão mais velho, músico, desaparece voltando para casa, no dia da queda da capital; seus tios também somem; seu cunhado, médico-cirurgião, é executado ao se apresentar como voluntário nos hospitais ocupados; e 0 pequeno Rithy, como várias crianças de sua idade, entre a infância e a adolescência, vai trabalhar nos arrozais e, depois, como coveiro de hospital.

Esse momento da história, que antecede as mortes em massa, é evocado por Rithy Panh em dois filmes de ficção - Les gens de la rizière (0 povo dos arrozais, 1994) e Gibier d'élevage (Caça de cativeiro, 2011). 0 primeiro filme é repleto de informações autobiográficas, confirmadas em seu livro recente, L'élimination (A eliminação, 2011). Em $O$ povo dos arrozais, um casal com sete filhas - como os pais de Rithy Panh, que tiveram três meninos e sete meninas -, luta pela sobrevivência no campo. 0 personagem do pai, Panh Lauv, tem o mesmo nome e sobrenome do pai do cineasta. Já em Caça de cativeiro, transposição do romance japonês de Kenzaburo Oe para o Camboja de 1972, embora não haja, ali, nenhum elemento diretamente inspirado da história pessoal de Rithy Panh, o filme é, no entanto, entrecortado de imagens documentais que surgem em meio à ficção, como flashes de uma memória extradiegética. São cenas de bombardeios aéreos norte-americanos com napalm que, inseridas na montagem, testemunham sobre a guerra, enraizando a narrativa ficcional na grande história. Por meio dessas imagens da guerra, uma delas, aliás, utilizada em 0 fundo do ar é vermelho (Chris Marker, 1977), Rithy Panh solicita ao espectador uma atenção especial ao fato histórico narrado em seu filme, mesmo que de forma romanesca, como acontece em Gibier d'élévage.

Com o fim do regime de Pol Pot, Rithy Panh abriga-se nos campos de refugiados da Tailândia, se esconde nas florestas e consegue chegar até Marselha, na França, onde viviam os únicos sobreviventes de sua família, quatro de seus nove irmãos, que estavam fora do Camboja, estudando, quando a revolução começou. Emudecido pela guerra, como ele conta em seu livro, Panh reaprende a falar em francês, faz seus estudos de cinema em Paris e retorna ao Camboja no final dos anos 1980 para rodar seu primeiro longametragem, Site 2 (1989), sobre o sofrimento de uma família cambojana em um campo de refugiados tailandês, perto de onde ele vivera. Ali, começaria um laborioso trabalho de resgate de sua própria história, através do enfrentamento da história de Outrem - refugiado, sobrevivente, torturador, carcereiro, chefe de polícia, familiares 
de mortos e desaparecidos, crianças abandonadas, homens e mulheres destruídos. Ao mesmo tempo em que ele encontra as testemunhas vivas da história, o cineasta procede a uma busca de imagens e documentos produzidos pelo Khmer Vermelho, material que será sistematicamente associado em seus filmes às falas das pessoas filmadas.

Com 0 apoio do INA, 0 instituto nacional do audiovisual francês, Rithy Panh reuniu imagens produzidas pela televisão francesa ou provenientes de outros países, criando o centro de fontes audiovisuais Bophana, em Phnom Penh, hoje com mais de 3 mil arquivos à disposição do público, compostos por filmes, fotografias, jornais televisivos e emissões radiofônicas. Rithy Panh salvou da destruição os arquivos da polícia e as imagens de propaganda do regime de Pol Pot. Sua obra participa da organização da fala dos sobreviventes, dos algozes e das novas gerações, massacradas pela pobreza. Da mesma forma que 0 filme Shoah (Claude Lanzmann, 1985) em relação ao genocídio dos judeus, sua obra deu um nome ao inominável, àquilo que 0 Camboja talvez tivesse preferido esquecer - o genocídio, o extermínio, a eliminaçã $0^{1}$. Rithy Panh reconstruiu-se sobre ruínas: arquivos, lugares da história, falas de sobreviventes. Uma tristeza infinita atravessa suas ficções e documentários, e cada um de seus filmes reitera a escrita de uma micro-história cambojana, que passa pela elaboração de seu próprio testemunho.

\section{0 sobrevivente}

Na obra de Rithy Panh, a escrita da história na primeira pessoa não remete a uma subjetividade ou a uma voz que diz "eu", mas ao testemunho do outro - as vítimas, os mortos e seus algozes, que testemunham diante do cineasta. $\mathrm{E}$ se a "pretensa subjetividade é o outro, no lugar de mim mesmo, ela não é mais subjetiva do que objetiva" (BLANCHOT, 1980, p. 48). Outrem se impõe diante da câmera, como uma evidência material da história. É com essa objetividade historiadora que Rithy Panh filmou os sobreviventes do genocídio cambojano, como se, através deles, ele pudesse dar 0 seu próprio testemunho do que viveu.

Somente duas pessoas saíram vivas do centro de extermínio e tortura denominado S21, em Phnom Penh, onde 12.380 pessoas foram torturadas e, depois, executadas. Um dos sobreviventes é 0 pintor Vann Nath, que fez vários quadros com representações do suplício dos prisioneiros. Ele aparece nos três documentários que Rithy da guerra, diziam "a Coisa". A partir do filme, em todas as línguas, o mundo inteiro começou a designar o massacre dos judeus como "a Shoah", que em hebraico quer dizer catástrofe, destruição, aniquilamento. 0 cinema atribuía, assim, um nome a um acontecimento ainda recente demais para ser nomeado com a precisão histórica exigida. Rithy Pahn, que admira o trabalho de Lanzman e que mais tarde buscaria algo similar em sua obra, intitulou seu livro autobiográfico A eliminação, outro significado do termo "shoah". 
Panh dedicou a essa prisão. Em Bophana (1996), o primeiro filme da trilogia, Nath entra em cena por acaso. Nas dependências da prisão, hoje transformada no Museu do Genocídio, Rithy Panh filmava Houy, um antigo torturador, encarregado da segurança em S21, quando Nath, que se servia do local como ateliê, voltou para buscar uns pincéis esquecidos ali. Imediatamente, ele reconhece em Houy o seu torturador. Nath se aproxima dele, coloca a mão no seu ombro e o conduz ao interior do museu, onde estão expostos seus quadros, representando as diversas situações de execução, tortura e confinamento de prisioneiros que ele presenciou ou sofreu. Com delicadeza, Nath pede a Houy que confirme se são verdadeiras ou não as cenas que ele pintou de memória ou que apenas imaginou como poderiam ter sido, nas ocasiões em que estava de olhos vendados ou em uma cela contígua à dos supliciados. De costas para a câmera, os dois homens param diante de cada quadro e, a cada vez, Nath pergunta ao antigo policial se as cenas representadas aconteceram realmente daquela forma. Houy confirma a veracidade do conteúdo de cada um dos quadros, e os dois homens saem do museu lado a lado, silenciosos, como haviam entrado.

Rithy Panh disse, depois, que jamais teria coragem de promover esse tipo de encontro e que, ao contrário, tomava, inclusive, precauções para que isso não acontecesse, filmando os antigos carcereiros e os sobreviventes de S21 em horários diferentes. Mas a reação de Nath diante de seu torturador muda o rumo das filmagens de Bophana, oferecendo ao cineasta bem mais do que um plano-sequência de seis minutos, de grande tensão. Ao tomar para si a responsabilidade de conduzir a fala do antigo policial, o pintor Vann Nath deu a Rithy Panh um método de abordagem humanista do testemunho do inimigo, método que o cineasta irá aperfeiçoar ao longo da série sobre a prisão S21. Com seu gesto, Nath retira 0 antigo policial de um registro discursivo da fala - que consiste em negar ou em afirmar acusações - e leva-o para um outro lugar, em que 0 testemunho não é mais simplesmente elaborado frente a uma câmera, mas diante dos próprios vestígios materiais do passado, ou seja, outros testemunhos possíveis, o de Nath e o de seus quadros. Menos do que uma informação, o que se espera do expolicial, com a situação criada, é um olhar sobre os vestígios de um passado comum, que religa 0 torturador ao torturado. Como disse Derrida, "0 testemunho é, às vezes, silencioso, e solicita ao corpo alguma coisa que não tem direito à fala" (2005, p. 34)

Seis anos depois de Bophana, Rithy Panh faria com Nath o segundo filme da trilogia e, talvez, o mais importante de toda a sua obra: S21, a máquina de morte Khmer Vermelho (2002). Aqui, a situação provocada por Nath naquele encontro casual torna-se um verdadeiro dispositivo de resgate da memória e de mise en scène do testemunho. Homem calmo e generoso, Nath passa a mediar, no lugar de Rithy Panh, a fala das pessoas filmadas. Nath e Houy reaparecem, os 
arquivos de S21 utilizados em Bophana - retratos de prisioneiros e documentos escritos - também são retomados, e mais cinco outros interrogadores são convidados, juntamente com Houy, a visitar as dependências da antiga prisão, conhecer os documentos, analisar o que se passou e, em alguns momentos, refazer os gestos cotidianos do trabalho. Eles examinam os documentos, fazem leituras em voz alta desse material e mostram como procediam, misturando narração, encenação e relato pessoal de suas versões dos fatos. Diante de Nath, os antigos carcereiros e torturadores não podem mais mentir. Ou podem, mas, nesse caso, a mentira encontra resistência no rosto do sobrevivente, e a falsidade do testemunho fica estampada na tela. "Aí está uma das junções das problemáticas do segredo, da responsabilidade e do testemunho. Não há mentira ou perjúrio sem responsabilidade, não há responsabilidade sem consciência de si" (DERRIDA, 2005, p. 41).

\section{Graças à presença de Nath entre os} interrogadores, Rithy Panh pode observar a confrontação entre os diferentes personagens da história. Com sua presença, Nath protege 0 cineasta de uma exposição excessiva. Segundo Rithy Panh, foi preciso muitos anos, muitos encontros, muitas lágrimas e leituras, para domesticar a violência inoculada em seu corpo: "o mal que me fizeram está em mim. Ele está aí, potente. Ele me espreita”. E não é por outra razão que ele escolheu o cinema: "ele mantém minhas mãos nos bolsos" (PANH, 2011, p. 17). Nath interpõe-se entre Rithy Panh e os homens de S21 e é ele também que ampara Chum Mey, o outro sobrevivente da prisão que, deprimido, não consegue falar. Diante dos muros de S21, apoiado em Nath e de costas para a câmera, Chum Mey encontra nas lágrimas o único testemunho possível. 0 tempo todo, em S21, Rithy Panh delega a Nath a condução das cenas, misturando os papéis de quem filma e de quem é filmado. E quando, durante as filmagens de S21, antigos quadros do Khmer Vermelho apareceram, ameaçando a equipe e os personagens com machados e foices, Rithy Panh largou a câmera e gritou: "Eu sei quem vocês são e onde vocês trabalharam. Você era torturador. Não negue. Você era carcereiro. Você era mensageiro. Vocês acham que eu venho assim, sem me preparar?" (2011, p. 24-25). Aqui, não há escrita possível da história sem uma necessária tomada de posição do presente em relação ao passado, sem uma projeção de si mesmo no testemunho de Outrem.

\section{Os mortos}

Sobrevivente de Auschwitz, o escritor Primo Levi disse que os mortos são os únicos capazes de um testemunho total e que os sobreviventes testemunhariam "por delegação", no lugar dos que morreram: "os que viram a Górgona, 
não voltaram para contar (...) são eles, os mulçumanos, os engolidos, as testemunhas integrais, aqueles cujo depoimento teria tido um significado geral" (LEVI, 1989, p. 82). Ao retomar os textos de Primo Levi, em seu livro sobre as relações entre 0 testemunho e 0 arquivo, Agamben, avança, no entanto, em outra direção: "Aquele que se encarrega de testemunhar por eles (os mortos), sabe que ele deverá testemunhar sobre a impossibilidade de testemunhar" (2003, p. 36). 0 testemunho situar-se-ia, então, nas lacunas existentes entre a possibilidade e a impossibilidade de dizer. É por isso que Agamben, diferentemente de Primo Levi, vê o testemunho não apenas como falta, mas também como sobra. A testemunha é "o que resta de Auschwitz". Ela é, ao mesmo tempo, o sobrevivente e 0 silêncio da morte que 0 acompanha. Na mesa de montagem de Rithy Panh, vê-se uma alternância constante entre esses dois aspectos do testemunho evocados por Agamben. À voz entrecortada de soluços dos vivos, que a dor impede de testemunhar, segue-se, na montagem de Panh, a eloquência do silêncio das imagens dos mortos, que ainda testemunham, apesar de tudo.

\section{Bophana, uma tragédia cambojana, filme que} dá origem à trilogia de $S 21$, conta a história da jovem Bophana, torturada e assassinada naquela prisão. Seu crime: ter escrito cartas de amor ao seu marido, Ly Sitha, um jovem budista, que deixou o monastério e alistou-se como soldado da revolução. Ele também foi preso e executado em S21, pelo mesmo motivo que sua mulher. Nos arquivos da prisão, Rithy Panh encontrou as cartas dos dois, fotografias e a confissão de Bophana, extraída sob intensos interrogatórios, os quais duraram várias semanas. Bophana era uma mulher bela, instruída, delicada e casada com um simpatizante da revolução. Não havia nada em sua história pessoal que justificasse, aos olhos da polícia política, sua prisão e execução. Então, os homens de S1 torturaram-na até obter dela, por escrito, a falsa confissão de que ela e seu marido seriam agentes da CIA. A técnica era aplicada de maneira sistemática na tortura, e a história de Bophana coincide com a de milhares de outras vítimas executadas em S21, depois de assinarem, sob interrogatório, confissões inventadas. Hoje, Bophana é um símbolo da tragédia cambojana, e a referência a seu nome ou a presença de sua fotografia causa um particular desconforto aos antigos torturadores de S21, filmados por Panh.

Graças aos arquivos, os mortos, que, por definição, não podem mais testemunhar, ressurgem, paradoxalmente, entre os vivos, como a testemunha por excelência. As cartas trocadas entre Bophana e Sitha são lidas, no filme, em língua khmer, por uma voz feminina e uma voz masculina, carregadas de compaixão. De Bophana sobraram essas cartas, sua confissão e duas fotografias: uma delas, de antes da prisão, em que vemos Bophana bonita e elegante, e a outra, tirada pela polícia, no momento de sua chegada a S21. É com esse acervo modesto que Rithy Panh dá voz a Bophana e Sitha em sua mesa de montagem. À narração em off das cartas de amor, ele associa imagens em preto e branco, sem som, 
de rapazes e moças nos campos de trabalho, feitas por cinegrafistas do Khmer Vermelho. Em contato com o texto das cartas de amor, essas imagens ganham um novo sentido. 0 falso testemunho da imagem de propaganda dá lugar, na montagem, a uma associação de ideias que produz, agora, a reverberação da fala inaudível dos mortos.

0 arquivo - entendido no sentido de Foucault, como um sistema de funcionamento das coisas ditas e não ditas, entre tradição e esquecimento, acumulação e desaparecimento (FOUCAULT, 1969, p. 171) -, quando trabalhado pela montagem, participa do testemunho. 0 retrato de Bophana é apenas um documento. Mas sua associação aos textos e falas, sua migração de um filme a outro permitem-lhe testemunhar. Em Gibier d'élevage, filme de ficção, um soldado Khmer Vermelho adolescente, embrutecido pela guerra, guarda consigo, escondido, uma foto de Bophana, sua "mãe". Inscrito, assim, na narrativa de ficção, 0 documento testemunha diante de personagens que não podem testemunhar. Essa mesma foto reaparecerá ainda no terceiro documentário da trilogia de S21, Duch, o mestre das forjas do inferno (2011), testemunhando, desta vez, diante de alguém que não quer testemunhar, no caso, Duch, o chefe da prisão S21. Rithy Panh coloca na frente dele duas fotos de Bophana. Inicialmente, Duch diz não se lembrar de nada, porém acaba por reconhecer a jovem, executada sob suas ordens:
"Duch me pergunta por que eu lhe mostro sempre fotos: - Pra que serve isso? Ele tem esse tom. Eu respondo: - Mas eles te escutam. Koy Tourn está aí. Bophana está aí... Para mim, eles te escutam" (PANH, 2011, p. 321-322).

0s mortos estão lá, nas imagens sobre a mesa. Eles encaram Duch e interpelam-no, em silêncio. Ele hesita, esfrega o rosto, desvia o olhar, mas não pode escapar ao contracampo insistente do passado que Rithy Panh coloca à sua frente, antecipando nas filmagens a montagem dos documentos. Por fim, a lembrança vem graças à insistência de Rithy Panh em convocar os mortos, gesto da montagem também presente na dedicatória de seus filmes. Bophana é dedicado ao "Tio Keun, vítima de Tuol Slegn, S21, e a Hiran, desaparecido". Duch, o mestre das forjas do inferno é dedicado ao pai do cineasta, Panh Lauv, "por sua integridade, sua coragem, sua dignidade", ou seja, tudo o que faltou a Duch'. S21, a máquina de morte é dedicado simplesmente "à memória...", breve inscrição que aparece sobre a própria imagem do esquecimento, a da antiga prisão, vazia, e o vento levando a poeira acumulada.

\section{0 inimigo}

Depois de ter filmado o testemunho dos mortos e 0 encontro dos sobreviventes com os seus algozes, faltava, ainda, à trilogia de S21 o desafio maior do face a face solitário com o inimigo, 
sem a mediação do testemunho de Nath, como havia acontecido nos dois primeiros filmes. Duch, o mestre das forjas do inferno, último documentário da série em torno da prisão, é a história de uma violenta confrontação do cineasta com Kaing Guek Eav, o "Duch", chefe do centro de extermínio de Tuol Sleng, a prisão que ficou conhecida pelo nome de "S21". Durante cerca de 300 horas, em huis clos, Rithy Panh irá filmar esse homem diante dos arquivos que ele mesmo produziu.

Vista retrospectivamente, a partir desse último filme, a trilogia de $S 21$ mostra a evolução gradual de um método de abordagem de uma das situações mais difíceis de serem enfrentadas no documentário: a da confrontação com o inimigo. Ao abordar 0 assunto em um número especial da revista Images documentaires, Catherine Blangonnet refere-se ao problema como "um dos limites do cinema documentário" (1995, p. 3). Ela se pergunta se é possível filmar um inimigo sem utilizar os métodos da propaganda, afeitos à caricatura e à imagem diabólica. Habituado a filmar a extrema-direita francesa, Jean-Louis Comolli diz, sobre isso, que "0 cinema só pode responder à guerra por uma crítica da guerra. Só resta ao cinema atribuir rosto humano ao inimigo" $(1995,55)$.

Exposição da humanidade do rosto filmado: a fórmula resumiria a obra de Rithy Panh, que evolui entre a restauração das ruínas do rosto das vítimas e a retirada da máscara do rosto dos algozes. Sua abordagem do testemunho, iniciada com Vann Nath, em Bophana, e aperfeiçoada durante três anos de filmagem com carcereiros e torturadores em S21, a máquina de morte, preparou-o para o encontro com o inimigo maior, 0 mandante dos crimes. 0 filme é pensado para que Duch possa, enfim, assumir perante seus semelhantes o seu papel na história.

\section{As filmagens de Duch, o mestre das forjas do} inferno têm início em 2009, quando um tribunal internacional começava a julgar o chefe de S21, acusado pela morte de 12.380 pessoas. Duch seria o primeiro quadro do Khmer Vermelho a ser julgado, e Rithy Panh retornou ao Camboja para filmá-lo, entre o tribunal e a prisão. Estudante brilhante e antigo professor de Matemática, Duch tornou-se chefe da polícia política do Khmer Vermelho ainda na clandestinidade, no maquis, onde ele formou os futuros torturadores e carcereiros de S21, recrutados entre os adolescentes órfãos, pobres e analfabetos do meio rural. Ao ser transferido para a capital, ele leva consigo esses jovens e transforma um antigo colégio na prisão S21, onde serão eliminados os quadros dissidentes da Angkar, a organização revolucionária, e milhares de civis.

Nath não está mais presente nas filmagens, e Rithy Panh instala, entre Duch e a câmera, uma mesa repleta de documentos, a maioria encontrada nos arquivos de S21: fotografias ampliadas de vítimas ou de revolucionários importantes, confissões de prisioneiros extraídas sob tortura e anotadas por 
Duch, relatórios, cartazes com slogans do Khmer Vermelho, os "cadernos pretos" de S21, com sua contabilidade da eliminação, e um pequeno computador com cenas do filme S21, a máquina de morte, em que os interrogadores mencionam com frequência o nome do chefe da prisão. Ao longo de todo o filme, o relato de Duch terá por contraplano não o seu entrevistador, mas 0 apelo mudo desses documentos. "Às vezes, é útil pôr um sinal nas mãos daquele que filmo. É uma forma de dizer-lhe: cuidado, eu sei mais do que você pensa, não minta" (PANH, 2011, p. 97-98). A situação é criada para levar Duch a dizer a verdade. E desde o primeiro dia, Panh entregou a Duch cerca de cinquenta páginas. "Se eu faço o carrasco sentarse ao lado de 4.000 documentos de arquivos, isso muda seu modo de pensar", já dizia Rithy Panh dez anos antes de rodar esse filme (2001, p. 383). Em um dispositivo fechado, austero, com apenas dois enquadramentos, de frente e ligeiramente de perfil, Rithy Panh filma Duch diante de um vasto material de arquivo. "Durante horas, ele fala sem dizer nada. Depois, ele avança, reconhece uma foto. Se entrincheira. (...) Duch se esquiva. Solta meias-verdades. Eu nunca procuro acuá-lo. Mas ele se interrompe. Graças ao cinema, a verdade surge: a montagem contra a mentira" (PANH, 2011).

A cada esquiva de Duch, Rithy Panh responde com os documentos, dispostos de maneira organizada sobre a mesa. Duch lê alguns slogans em voz alta: "é melhor matar um inocente do que deixar escapar um inimigo"; "te guardando, não ganhamos nada; te eliminando, não perdemos nada". 0 contato com os documentos parece despertar o passado, e o vocabulário técnico do antigo chefe de polícia ressurge na fala de Duch: os verbos "eliminar", "destruir" aparecem no lugar de "matar", "executar". Duch explica, então, como a linguagem do extermínio foi transferida para o papel: "os prisioneiros eram inimigos, não eram seres humanos". Ele conta como foi o doutrinamento ideológico que recebeu, desde jovem, e como transmitiu esse conhecimento aos seus subalternos. A fala é "despertada, amplificada, ramificada pelos documentos" (PANH, 2011, p. 97-98). Ao ouvir os relatos dos antigos torturadores no filme $S 21$, ele reage, inicialmente, com um riso nervoso, contesta o que dizem e, por fim, controla-se. Diante dos livros de registro da prisão, Duch resgata as etapas sucessivas do suplício dos prisioneiros, comenta as assinaturas que os documentos vão recebendo em seus trâmites administrativos e aponta as anotações feitas por ele, à mão, com indicações para dar continuidade à tortura ou proceder à eliminação. É o método de filmagem que retira do personagem alguma verdade. "Duch tem uma fraqueza: ele não conhece o cinema. Ele não acredita no jogo de repetições, de cruzamentos. Ele não sabe que a montagem é uma política e uma moral. E no tempo, há somente uma verdade" (PANH, 2011, p. 314).

A filmagem de Duch avança, assim, como um combate, uma luta política, um corpo a corpo entre duas inteligências, tendo os documentos como barreira ao assassínio e à mentira. É preciso 
"dar corpo e presença ao inimigo, para que ele apareça em sua potência" (COMOLLI, 2004, p. 400) ou em sua impotência, no caso de Duch, já encarcerado no momento das filmagens e, em seguida, condenado à prisão perpétua. Privado de sua força, esvaziado de sua potência, 0 inimigo torna-se, desta maneira, um de nós, "o que nós todos somos, o vivo mal-estar de um sujeito abalado" (COMOLLI, 1995, p. 56). Rithy Panh filma o inimigo expondo-o em sua condição intrinsecamente humana, a única que lhe permite assumir sua responsabilidade pelos crimes cometidos.

0 dispositivo criado por Rithy Panh para filmar esse chefe de polícia, com a mediação dos arquivos, levanta a questão 'levinasiana' do "rosto ético", entendido como fronteira moral que inibe a violência contra Outrem. Exposto, ameaçado, "como que nos convidando a um ato de violência", o rosto é, ao mesmo tempo, "0 que nos impede de matar" (LEVINAS, 1982, p. 90). Em sua exposição direta, nua e vulnerável, o rosto se mostra em sua "pobreza essencial", interpelando-nos como uma ordem, um mandamento: "não matarás!". Nenhum sistema de entrevista poderia dar conta da complexidade da relação intersubjetiva que o rosto ético instaura, relação responsável, mas também assimétrica, que não passa pela reciprocidade. Rithy Panh se posiciona fora de campo como responsável pela verdade de Duch, mesmo que ele minta. A recíproca é problema do outro.
0 tribunal internacional que julgava Duch naquele momento não convocou as imagens de arquivo, com a alegação de que elas não provavam nada. Rithy Panh, que não buscava provas do crime ou acareações, obtém de Duch um testemunho possível, mesmo que, ou sobretudo, silencioso, mentiroso, técnico. Dos interstícios de sua fala repetitiva, pois sempre relançada com 0 auxílio das mesmas imagens, emerge um testemunho vivo, nunca antes formulado, proveniente da associação imediata entre passado e presente que sua relação com os documentos desencadeia. Duch acaba falando de questões pouco conhecidas, como a retirada de sangue das prisioneiras como método econômico de execução, as vivissecções em aulas de anatomia, 0 assassinato das crianças de pais executados, os estupros de mulheres. Rithy Panh insistiu junto à corte internacional sobre a necessidade de convocação dos arquivos: "as imagens farão a história, elas dirão ao mundo 0 que os culpados fizeram - pensem em Nuremberg! Há uma pedagogia e uma universalidade da imagem" (PANH, 2011, p. 25). No entanto, ele não foi ouvido e as imagens não foram utilizadas no processo. Para Rithy Panh, esses registros deveriam ter sido apresentados ao acusado, para que ele se explicasse diante do tribunal, como acontece no filme:

Faltam mesmo provas? Não. Há dezenas de fotografias tiradas pelos camaradas de S21. Há até mesmo fotografias de um suicidado; ou de um prisioneiro ferido com uma bala na nuca, porque tentou resistir. Esse homem vai morrer e, aliás, 
Duch me diz imediatamente o nome dele. Ele me descreve 0 acidente. Que confissão! (...) Um tal documento deve ser analisado, esmiuçado, visto em seu contexto. Ele não é uma prova em si. É a história que ele contém que é uma prova, mas essa história não se oferece espontaneamente. É preciso procurá-la. (PANH, 2011, p. 306).

A abordagem dos documentos por parte de Rithy Pahn aproxima o seu trabalho do método dos historiadores, cientes, desde Foucault, da necessidade de decifrar os arquivos, de organizálos de uma certa forma para que a história neles contida venha à tona: "o arquivo pode não contar a verdade, mas ele fala da verdade" (FARGE, 1997, p. 40). Enquanto o tribunal se contentava com o discurso de Duch, com suas respostas prontas, Rithy Panh obtinha do acusado uma fala desarmada, formulada a partir da confrontação com os documentos.

Rithy Panh conta que foi preciso vinte anos de amadurecimento, dele e de alguns membros de sua equipe, que também viveram o genocídio, antes de realizar S21, a máquina de morte do Khmer Vermelho. 0 tempo para encontrar a melhor distância e 0 discernimento necessário para fazer um filme sobre os mecanismos do crime, diz ele, é também o tempo de que precisavam para aprender a viver com a dor. "Quando se atravessa um genocídio, nunca se sai dele, completamente" (PANH, 2004, p. 14). Aliás, os psicanalistas interessados pela história se perguntam se a autobiografia dos sobreviventes não contribuiria para levar, alguns deles, ao suicídio, como aconteceu com Primo Levi ou com Sarah Kofman, por exemplo (ROSENBLUM, 2000).

Em seu livro autobiográfico L'élimination, coescrito com Christophe Bataille e publicado logo após as filmagens com Duch, Rithy Panh alterna, ainda, a narrativa de sua história pessoal com 0 relato dessa confrontação, como se agora fosse a sua vez de testemunhar diante do inimigo. E no documentário A imagem que falta (2013), baseado nesse mesmo livro, embora inteiramente narrado por uma voz off na primeira pessoa, a tragédia da família de Panh é sempre contada em alternância com a história do Camboja e com 0 auxílio das imagens de propaganda que ajudam a compor o tempo histórico da trilogia de $S 21.0$ ato de testemunho nunca é solitário e resulta sempre de um engajamento diante de alguém (Nath, Bophana, Houy, Duch). Ele é como um sermão, diz Derrida (2005, p. 45). Por isso, talvez, Rithy Panh tenha precisado de tantos anos para contar a história na primeira pessoa: ele estava por demais engajado na escuta do testemunho de Outrem.

\section{Referências}

AGAMBEN, G. Ce qui reste d'Auschwitz. Homo Sacer

III. Paris: Editions Payot et Rivages, 2003.

BLANCHOT, M. Lécriture du désastre. Paris: Gallimard, 1980.

BLANGONNET, C. "Editorial". Images documentaires $n^{0} 23$. Paris, 1995, p. 3.

COMOLLI, J.-L. “Comment filmer l'ennemi?". Voir et pouvoir. Lagrasse: Verdier, 2004, p. 387-400. 
COMOLLI, J.-L. "Mon ennemi préféré". Images documentaires $n^{0} 23$. Paris, 1995, p. 45-56.

DERRIDA, J. Poétique et politique du témoignage. Paris: Editions de l'Herne, 2005.

FARGE, A. Le goût de l'archive. Paris: Seuil, 1997.

FOUCAULT, M. L’Archéologie du savoir. Paris:

Gallimard, 1969.

LEANDRO, A. "Um arquivista no Camboja". 0 cinema de Rithy Panh. Rio de Janeiro: CCBB, 2013, p. 185-197.

LEVI, P. Les Naufragés et les Rescapés. Paris: Gallimard, 1989.

LEVINAS, E. Ethique et infini. Paris: Fayard, 1982.

PANH, R. L'élimination. Paris: Grasset, 2011.

PANH, R. "Je suis un arpenteur de mémoire". Cahiers du cinema $\mathrm{n}^{0} 587$, janvier 2004, p. 14-17.

PANH, R. "La parole filmée. Pour vaincre la terrer". Communications. Le parti pris du document, $\mathrm{n}^{0} 71$, 2001, p. 373-394.

ROSENBLUM, R. "Peut-on mourir de dire? Sarah Kofman, Primo Levi”. Revue Française de Psychanalyse. Devoir de mémoire: entre passion et oubli. Tome LXIV, 1, 2000, p. 113-137. 


\begin{tabular}{|c|c|}
\hline $\begin{array}{l}\text { History in first person: } \\
\text { about Rithy Panh's method }\end{array}$ & $\begin{array}{l}\text { La historia en primera persona: } \\
\text { sobre el trabajo de Rithy Panh }\end{array}$ \\
\hline $\begin{array}{l}\text { Abstract } \\
\text { A survivor of Khmer Rouge's revolution that killed } \\
\text { most of Kampuchea's population in the years 1975- } \\
\text { 1979, the filmmaker Rithy Panh dedicated his work } \\
\text { to that tragical chapter of the history of the country. } \\
\text { Why only in his last film - Limage manquante } \\
\text { (2013) - a narrative where Kampuchea's history is } \\
\text { mixed with his family life, Panh used the narrative in } \\
\text { first person? Before being able to use "I" in his films } \\
\text { it was necessary first to talk about the documents } \\
\text { and the oral sources, in a thorough work of listening } \\
\text { that Panh started in the late 1980's. } \\
\text { Keywords } \\
\text { Rithy Panh. Archives. Historical memory. }\end{array}$ & $\begin{array}{l}\text { Resumen } \\
\text { Sobreviviente de la revolución Khmer Rouge que } \\
\text { eliminó gran parte de la población de Camboya entre } \\
1975 \text { y 1979, el cineasta Rithy Panh dedicó su obra } \\
\text { a este trágico capítulo de la historia de su país. } \\
\text { ¿Por qué, entonces, sólo después de que ya se había } \\
\text { establecido como uno de los más grandes cineastas } \\
\text { contemporáneos, con una veintena de películas, } \\
\text { toma en el documental Limage manquante (2013), } \\
\text { una narración en primera persona? La historia del } \\
\text { genocidio camboyano se confunde con la historia } \\
\text { de su propia familia y, antes de que pudiera decir } \\
\text { "Yo" en el desarrollo de una memoria histórica, era } \\
\text { necessário, en primer lugar, el testemonio de los } \\
\text { documentos y de las fuentes orales. } \\
\text { Palabras clave } \\
\text { Rithy Panh. Archivos. Memoria histórica. }\end{array}$ \\
\hline
\end{tabular}




\section{Expediente}

A revista E-Compós é a publicação científica em formato eletrônico da Associação Nacional dos Programas de Pós-Graduação em Comunicação (Compós). Lançada em 2004, tem como principal finalidade difundir a produção acadêmica de pesquisadores da área de Comunicação, inseridos em instituições do Brasil e do exterior.

\section{E-COMPÓS I www.e-compos.org.br I E-ISSN 1808-2599}

Revista da Associação Nacional dos Programas de Pós-Graduação em Comunicação.

Brasília, v.19, n.3, set./dez. 2016.

A identificação das edições, a partir de 2008, passa a ser volume anual com três números.

Indexada por Latindex I www.latindex.unam.mx

\section{CONSELHO EDITORIAL}

Alexandre Farbiarz, Universidade Federal Fluminense, Brasil Alexandre Rocha da Silva, Universidade Federal do Rio Grande do Sul, Brasil Ana Carolina Escosteguy, Pontifícia Universidade Católica do Rio Grande do Sul, Brasil Ana Carolina Rocha Pessôa Temer, Universidade Federal de Goiás, Brasil Ana Regina Barros Rego Leal, Universidade Federal do Piauí, Brasil Andrea França, Pontifícia Universidade Católica do Rio de Janeiro, Brasil André Luiz Martins Lemos, Universidade Federal da Bahia, Brasil Antonio Carlos Hohlfeldt, Pontifícia Universidade Católica do Rio Grande do Sul, Brasil Arthur Ituassu, Pontifícia Universidade Católica do Rio de Janeiro, Brasil Álvaro Larangeira, Universidade Tuiuti do Paraná, Brasil Ângela Freire Prysthon, Universidade Federal de Pernambuco, Brasil César Geraldo Guimarães, Universidade Federal de Minas Gerais, Brasil Cláudio Novaes Pinto Coelho, Faculdade Cásper Líbero, Brasil Daisi Irmgard Vogel, Universidade Federal de Santa Catarina, Brasil Denize Correa Araujo, Universidade Tuiuti do Paraná, Brasil

Eduardo Antonio de Jesus, Pontifícia Universidade Católica de Minas Gerais, Brasil Daniela Zanetti, Universidade Federal do Espirito Santo, Brasil

Eduardo Vicente, Universidade de São Paulo, Brasil

Elizabeth Moraes Gonçalves, Universidade Metodista de São Paulo, Brasil Erick Felinto de Oliveira, Universidade do Estado do Rio de Janeiro, Brasil Francisco Elinaldo Teixeira, Universidade Estadual de Campinas, Brasil Francisco Paulo Jamil Almeida Marques, Universidade Federal do Paraná, Brasil Gabriela Reinaldo, Universidade Federal do Ceará, Brasil

Goiamérico Felício Carneiro Santos, Universidade Federal de Goiás, Brasil Gustavo Daudt Fischer, Universidade do Vale do Rio dos Sinos, Brasil Herom Vargas, Universidade Municipal de São Caetano do Sul, Brasil Itania Maria Mota Gomes, Universidade Federal da Bahia, Brasil Janice Caiafa, Universidade Federal do Rio de Janeiro, Brasil Jiani Adriana Bonin, Universidade do Vale do Rio dos Sinos, Brasil
José Afonso da Silva Junior, Universidade Federal de Pernambuco, Brasil José Luiz Aidar Prado, Pontifícia Universidade Católica de São Paulo, Brasil Juçara Gorski Brittes, Universidade Federal de Ouro Preto, Brasil Kati Caetano, Universidade Tuiuti do Paraná, Brasil Lilian Cristina Monteiro França, Universidade Federal de Sergipe, Brasil Liziane Soares Guazina, Universidade de Brasilia, Brasil Luíza Mônica Assis da Silva, Universidade de Caxias do Sul, Brasil Luciana Miranda Costa, Universidade Federal do Pará, Brasil Malena Segura Contrera, Universidade Paulista, Brasil Monica Martinez, Universidade de Sorocaba, Brasi Maria Ataide Malcher, Universidade Federal do Pará, Brasil Marcia Tondato, Escola Superior de Propaganda e Marketing, Brasil Marcel Vieira Barreto Silva, Universidade Federal da Paraíba, Brasil Maria Clotilde Perez Rodrigues, Universidade de São Paulo, Brasil Maria das Graças Pinto Coelho, Universidade Federal do Rio Grande do Norte, Brasil Mauricio Ribeiro da Silva, Universidade Paulista, Brasil

Mauro de Souza Ventura, Universidade Estadual Paulista, Brasil Márcio Souza Gonçalves, Universidade do Estado do Rio de Janeiro, Brasil Micael Maiolino Herschmann, Universidade Federal do Rio de Janeiro, Brasil Mirna Feitoza Pereira, Universidade Federal do Amazonas, Brasil Nísia Martins Rosario, Universidade Federal do Rio Grande do Sul, Brasil Potiguara Mendes Silveira Jr, Universidade Federal de Juiz de Fora, Brasil Regiane Regina Ribeiro, Universidade Federal do Paraná, Brasil Rogério Ferraraz, Universidade Anhembi Morumbi, Brasil Rose Melo Rocha, Escola Superior de Propaganda e Marketing, Brasil Rozinaldo Antonio Miani, Universidade Estadual de Londrina, Brasil Sérgio Luiz Gadini, Universidade Estadual de Ponta Grossa, Brasil Simone Maria Andrade Pereira de Sá, Universidade Federal Fluminense, Brasil Veneza Mayora Ronsini, Universidade Federal de Santa Maria, Brasil Walmir Albuquerque Barbosa, Universidade Federal do Amazonas, Brasil

\section{CONSELHO CIENTÍFICO}

Cristiane Freitas Guttreind, Pontifícia Universidade Católica do Rio Grande do Sul, Brasil Eduardo Morettin, Universidade de São Paulo, Brasil Felipe Costa Trotta, Universidade Federal Fluminense, Brasil Irene de Araújo Machado, Universidade de São Paulo, Brasil

\section{COMISSÃO EDITORIAL}

Eduardo Antonio de Jesus, Pontifícia Universidade Católica de Minas Gerais, Brasil Osmar Gonçalves dos Reis Filho, Universidade Federal do Ceará, Brasil

\section{CONSULTORES AD HOC}

Geane C. Alzamora, Universidade Federal de Minas Gerais, Brasil Teresinha Cruz Pires, Pontifícia Universidade Católica de Minas Gerais, Brasil

\section{EQUIPE TÉCNICA}

ASSISTENTE EDITORIAL Márcio Zanetti Negrini

REVISÃO DE TEXTOS Press Revisão

EDITORAÇÃO ELETRÔNICA Roka Estúdio

IMAGEM DE CAPA Silas de Paula

\section{COMPÓS I www.compos.org.br}

Associação Nacional dos Programas de Pós-Graduação em Comunicação

Presidente

Edson Fernando Dalmonte

Programa de Pós-Graduação em Comunicação

e Cultura Contemporânea - UFBA

edsondalmonte@uol.com.br

Vice-presidente

Cristiane Freitas Gutfreind

Programa de Pós-Graduação em Comunicação Social - PUC-RS cristianefreitas@pucrs.br

Secretário-Geral

Rogério Ferraraz

Programa de Pós-Graduação em Comunicação

Universidade Anhembi Morumbi

rogerioferraraz@anhembimorumbi.edu.br

CONTATO I revistaecompos@gmail.com 